\title{
SENTIDOS DA MATERNIDADE NA PRISÃO: UM ESTUDO EMPÍRICO NA COLÔNIA PENAL FEMININA DE BUÍQUE/PE
}

\section{SENSES OF MATERNITY IN PRISON: A STUDY IN THE FEMININE PENAL COLONY OF BUÍQUE/PE}

\section{FERNANDO DA SILVA CARDOSO}

Doutorando em Direito - Pontifícia Universidade Católica do Rio de Janeiro (2016). Mestre em Direitos Humanos - Universidade Federal de Pernambuco (2015). Pósgraduado em Direitos Humanos - Universidade Federal de Campina Grande (2015). Professor Assistente, Subcoordenador de Pesquisa e Extensão e membro do Núcleo Docente Estruturante do Curso de Direito da Universidade de Pernambuco - Campus Arcoverde.

\section{MARIA SIMONE GONZAGA}

Mestranda em Direito - Universidade Católica de Pernambuco. Bacharel em Direito Centro Universitário do Vale do Ipojuca. Advogada. Pesquisadora do Grupo de Estudos e Pesquisas Interdisciplinares sobre Direitos Humanos (GEPIDH). Extensionista no Projeto de Assessoria Jurídica Popular - (PROJURIS).

\section{RESUMO}

O presente artigo tem por objetivo apresentar algumas intersecções construídas sobre o sentido da maternidade no cárcere, perfazendo o quadro acerca das condições femininas com base do cotidiano investigado. De abordagem qualitativa, esta pesquisa empírica articula algumas categorias analíticas extraídas da investigação a partir da técnica de Análise do Conteúdo (BARDIN, 2011). Os resultados apresentados neste estudo indicam que o estabelecimento prisional estudado nega e/ou exclui a condição de "ser mãe/mulher" no cárcere por meio de processos que a despersonalizam e que subalternizam seus direitos reprodutivos. Conclui-se também 
que a maternidade é exercida a partir de meras regras de punição e/ou administração do espaço carcerário, sendo, mãe e criança, um mesmo corpo abjeto e objetificado neste espaço. Ainda, a pesquisa aponta que instrumentos importantes para a vivência dos direitos reprodutivos de mulheres mães presas, neste caso a Lei no 11.942/2009, não tem alcançado repercussão no sistema carcerário, e, assim, garantias relacionadas à permanência do(a) filho(a) com a mãe, sobre o aleitamento, a preparação e a separação entre mães e bebês e outros aspectos base são instrumentalizados a partir do subjetivismo dos(as) agentes estatais.

PALAVRAS-CHAVE: Direitos reprodutivos; Cárcere; Maternidade; Violações.

\section{ABSTRACT}

Thus, this article aims to present some built intersections on sense of motherhood in prison, making the picture about women's conditions on the basis of the investigated daily. Qualitative approach, this study articulates some extracted analytical categories of research from the content analysis technique (Bardin, 2011). The results presented in this study indicate that the studied prison deny and / or preclude the condition of "being a mother/woman" in prison through processes that depersonalize and exclude their reproductive rights. It also concludes that motherhood is exercised from mere rules of punishment and/or administration of the prison space, being, mother and child, the same body abject and objectified in this space. Still, the research shows that important instruments for the life of the reproductive rights of women imprisoned mothers, in this case the Law no. 11.942 / 2009, has not reached repercussion in the prison system, and thus guarantees related to the permanence of (a) child (a) with the mother on breastfeeding, preparation and separation of mothers and babies and other basic aspects are instrumentalized from the subjectivism of (the) state actors.

KEYWORDS: Reproductive rights; Prison; Maternity; Violations. 


\section{INTRODUÇÃO}

Este artigo apresenta parte dos resultados da pesquisa ${ }^{1}$ desenvolvida ao longo do ano de 2015 na Colônia Penal Feminina de Buíque, a qual teve como objetivo investigar sobre as peculiaridades e realidade envolvendo mães nesta prisão, visando discutir sobre a maternidade e o seu (não) exercício. Ainda, no sentido de observar as necessidades e como, de fato, o Estado se posiciona na aplicação das Leis vigentes que resguardam os direitos de mães e filhos, assegurando, no cárcere feminino, condições mínimas de assistência e subsistência.

A vivência dos direitos reprodutivos, em específico quanto à maternidade no cárcere, segundo as Leis vigentes, se dá a partir do estabelecimento de paralelos com fundamento na legislação em vigor, respeitando-se o dia a dia das presas e seus bebês, considerando os avanços no que diz respeito à saúde da mãe presa e do seu filho, bem como a previsão de espaços de creche e berçário. E, ainda, na possibilidade de extensão do tempo de permanência das crianças no cárcere até os 07 (sete) anos de idade incompletos.

A partir desses princípios, analisar o cárcere feminino, especialmente, no que se refere a vivência da maternidade em unidades prisionais, é uma importante abertura à problematização do atual quadro de (não)afirmação dos direitos reprodutivos de mulheres presas. Partindo da realidade prisional feminina e da (não)aplicabilidade da Lei em vigor, é importante perceber como esse quadro atinge mães e filhos, e até que ponto o crime cometido pelas mulheres assume, no estado de gravidez, um dupla penalização, estendendo-se também ao(a) filho(a).

A vivência dos direitos reprodutivos por mulheres/mães presas é condição determinante para a criação do vínculo entre elas e seus/suas filhos(as) e para a não negação de direitos humanos a ambos os sujeitos. A sexualidade e a saúde reprodutiva no ambiente prisional são concebidas de forma superficial e pontual, uma realidade que, muitas vezes, é julgada pois não são desenvolvidas políticas públicas com o intuito de proteger e respeitar o direito dessas mulheres.

\footnotetext{
1 Esta pesquisa, por ter lidado com seres humanos, conforme estabelece a Resolução no 466 de 2012 do Conselho Nacional de Saúde, foi apresentada ao Comitê de Ética do Centro Universitário do Vale do Ipojuca, sendo aprovada sua realização, conforme Parecer de № 1.267.649, emitido pelo referido órgão.
} 
Vê-se que, hoje, para que ocorra realmente o respeito a garantias base a mães presas, é necessário que a instituição prisional assegure um espaço adequado, dando apoio e auxílio a essas mães. Aspectos como higiene, estímulos ao bebê e amamentação são essenciais, levando-se sempre em consideração, nesse cenário, o melhor interesse da criança.

Dentre os questionamentos que deram origem a esta pesquisa, um deles se destaca: Quais as experiências e violações vividas pelas presas na Colônia Penal Feminina de Buíque/PE quanto a seus direitos reprodutivos? Entende-se como de extrema relevância a problematização desses direitos a partir do exercício da maternidade no cárcere. Do mesmo modo, o objetivo geral que orientou a pesquisa foi: compreender as experiências e violações vividas pelas presas na Colônia Penal Feminina de Buíque/PE quanto a seus direitos reprodutivos.

No sentido de instrumentalizar o referido estudo, os objetivos específicos eleitos foram: 1. Analisar a concepção de maternidade no cárcere; 2. Verificar as perspectivas e contribuições da Lei 11.942/2009 a garantir os direitos fundamentais da mulher mãe em situação de cárcere; e, 3. Identificar o cenário de graves violações de direitos da mulher mãe em situação de cárcere.

Quanto aos aspectos metodológicos do estudo, trata-se de uma pesquisa de caráter qualitativo, sendo classificada como: bibliográfica (em relação ao seu ponto de partida), e descritiva e exploratória (quanto aos seus fins). A coleta de dados deu-se a partir de análise documental e de entrevistas semiestruturadas com: Gestantes, lactantes e mulheres que foram mães na CPFB e seus/suas filhos/as já se encontravam com outros familiares, e, por último, com a Chefia Executiva da Colônia, os dados coletados foram lidos e categorizados a partir dos elementos da análise de conteúdo.

\section{INTERFACES ENTRE CÁRCERE, MATERNIDADE E CONDIÇÃO FEMININA}

Contextualizar as condições do cárcere feminino, indagando como é ser mulher e mãe neste ambiente, apresentando as peculiaridades nele existentes, é um importante caminho à discussão sobre a afirmação dos direitos que possuem as 
mulheres encarceradas, especialmente sobre questões de gênero e ligadas a direitos sexuais e reprodutivos.

As mulheres têm um histórico de lutas pelo seu reconhecimento como sujeitos de direito. No entanto, mesmo com todo o avanço do século XX, alguns fatores ainda impedem que homens e mulheres sejam vistos, em garantias, como iguais. Mesmo sendo um princípio fundamental, a igualdade de gênero ainda não é plena. Sobre a mulher sempre pairaram os olhos do patriarcado, inclusive nos dias de hoje.

A construção dos gêneros se dá através da dinâmica das relações sociais (SAFFIOTI, 1992). É na relação entre si que os seres humanos se constroem. No entanto, a condição feminina, nesse espaço, sempre foi marcada por processos de estigmatização e subalternidade. Em que pese a desigualdade patente, ao longo dos últimos anos, os movimentos feministas conquistaram vários avanços para concretização e efetivação dos direitos das mulheres.

Internacionalmente falando, em 1979 aconteceu a Convenção das Nações Unidas sobre a Eliminação de Todas as Formas de Discriminação contra a Mulher, documento que foi considerado um marco dos direitos humanos internacionais das mulheres. O eixo central da Convenção está na materialização da igualdade formal de tratamento entre homens e mulheres, reafirma a importância dos direitos feminis, dando novos horizontes a igualdade entre homens e mulheres, combatendo as persistentes formas de discriminação (ONU, 1979).

O ano de 1995 também marca um importante passo nesse processo. É na $4^{a}$ Conferência Mundial da Mulher que foram discutidos novos marcos à afirmação de direitos sexuais femininos. Contudo, os aspectos culturais, religiosos e de diferenciação de gênero ainda atrapalhavam e subalternizavam a mulher a partir de aspectos médico-biológicos.

Por outro lado, a 65. . Assembleia da Organização das Nações Unidas (ONU, 2010) expandiu esse debate ao estabelecer normas internacionais para o tratamento de mulheres encarceradas, as chamadas "Regras de Bangkok". Esse normativa estabeleceu princípios e regras para uma boa organização de estabelecimentos prisionais, buscando afirmar as peculiaridades de gênero no tratamento de mulheres 
em cumprimento de pena privativa de liberdade ${ }^{2}$. Com relação as mães presas, as Regras traçam parâmetros a um tratamento digno, no qual a mãe seja, por exemplo, ouvida no momento que precisar s separar dos(as) filhos(as), que tenham direito à saúde, que possa amamentar e que o momento da separação seja definido com base no princípio do melhor interesse da criança, dentre outras garantias.

Neste mesmo sentido é que a Convenção Interamericana para Prevenir, Punir e Erradicar a Violência contra a Mulher - Convenção de Belém do Pará passou a fazer menção a violência de gênero (em seu amplo sentido) como uma afronta aos direitos humanos. O sofrimento físico, sexual e/ou psicológico, considerando a violência como objeto de total repúdio, passa ser fortemente combatido, inclusive quanto a condição da mulher-mãe em situação em situação de cárcere. Essa peculiaridade se dá pelo fato de que, enquanto gestante, prevalece a condição de "criminosa", não é respeitado o momento em que ela se encontra, sendo visto e considerado apenas que esta cometeu um crime e deve ser punida por isso. Nesse cenário, a mãe presa não tem corpo, não é reconhecida como mulher, ela é duplamente penitenciada por ter, supostamente, colocado seu/sua filho(a) nessa condição.

Contudo, se a obrigação de proteção aos direitos fundamentais das mulheres presas é, no caso do Brasil, do Estado, é preciso que se esteja atento às necessidades das mães e à aplicação das leis vigentes. Quanto aos direitos que possuem as mulheres encarceradas, a saúde é uma questão chave, e que quase nunca é respeitada, o Estado não coloca em prática o que determina a Lei, realçando o caráter meramente punitivo que o constitui.

Como visto, tem-se no âmbito do direito inúmeros aspectos quanto as interfaces entre cárcere, maternidade e condição feminina. As mulheres grávidas em privação de liberdade deverão dispor de orientação e tratamento adequado, a elas devem ser asseguradas as mesmas orientações de uma mãe livre.

\subsection{TRAJETOS DA AFIRMAÇÃO DE DIREITOS SEXUAIS E REPRODUTIVOS DE MULHERES: ELEMENTOS PARA PENSAR A CONDIÇÃO FEMININA NO CÁRCERE}

\footnotetext{
${ }^{2}$ Apesar de, historicamente, o Brasil ser marcado por sistemáticas violações de direitos humanos no
} âmbito prisional, seja ele masculino ou feminino, o País ratificou, nesta ocasião, as Regras de Bangkok. 
Os direitos sexuais e reprodutivos são direitos fundamentais da pessoa humana, assim como o direito à vida, à liberdade e igualdade, tendo estes, garantia e proteção legal. Possuem características universais e indivisíveis, estão associados aos direitos políticos e civis, sendo proibido qualquer tipo de discriminação. Em tese, respeitá-los é nutrir uma sociedade justa, é saber conviver com as diferenças de gênero, tratando essas particularidades como complementares a garantias mais amplas. Entendemos que esses obstáculos se multiplicam quando se trata de afirmar garantias a mulheres presas, como discutiremos a seguir.

É após a $2^{\text {a }}$ Guerra Mundial, com o surgimento da Declaração Universal dos Direitos Humanos, em 1948, por meio da ONU, que se passa a tratar esses direitos como garantias de base universal, inerentes a toda e qualquer pessoa (ONU, 1948). Ao apontar que todo ser humano é titular de direitos, o princípio da indivisibilidade passa a sugerir a efetivação de direitos até então esquecidos, como no caso de direitos sexuais e reprodutivos de mulheres.

Décadas mais tarde, na Conferência Internacional da ONU sobre População e Desenvolvimento (CIPD), realizada na cidade do Cairo em 1994, é que são trazidas mudanças significativas nesse debate iniciado em 1948. Direitos humanos quanto à igualdade de gênero, planejamento familiar (baseado no controle de fecundidade que respeite a vontade dos pais) e outros mecanismos à afirmação de direitos sexuais e reprodutivos (ONU, 1994) ganham mais espaço. É a partir do Programa de Ação elaborado nessa ocasião que se estabelece que a saúde reprodutiva deveria ser buscada como um estado geral de bem-estar físico, mental e social à mulher, devendo essa condição ser disfrutada de forma plena, colocando a mulher livre de riscos e privações. Destaca-se, nesse quadro, o estabelecimento do direito de gerar o número de filhos que desejar, para tanto, devendo ter a garantia de acesso a informação e educação sobre o tema (RIOS, 2007, p.17), por exemplo.

Seguidamente, na IV Conferência Mundial sobre a Mulher que aconteceu em Pequim, em 1995, ratifica-se os acordos firmados no Cairo, distinguindo-se a autonomia entre direitos sexuais e direitos reprodutivos, passando-se a pensar estratégias especificas para cada campo. Assume-se a noção de que direitos sexuais garantiriam que qualquer pessoa pudesse viver sua vida sexual de forma livre de discriminação. Enquanto que, os direitos reprodutivos, assegurariam que todo sujeito 
poderia decidir livre e responsavelmente sobre se quer ter filhos e o número que deseja, como também deveria dispor de uma saúde pública de qualidade, (ONU, 1995), como forma de afirmar essas garantias.

Assim, quando observadas às necessidades das mulheres e colocadas em práticas tais parâmetros, as mulheres ganhariam, de fato, autonomia. A liberdade sexual/reprodutiva deve ser protegida como caminho a não discriminação de gênero. Nesse sentido, vê-se ser ainda um desafio esse cenário de vivência de direitos, especialmente no que concerne a mulher em situação de cárcere, ainda mais vulneráveis a violações e desrespeitos.

Portanto, debater sobre direitos sexuais e reprodutivos passa a assumir a feição de investigar as próprias discussões sobre direitos humanos das mulheres, tematizando a singularidade de poder livremente decidir quanto a ter ou não filhos, com quem manter relações sexuais e de ser dona do seu próprio corpo. Entendemos que a essência desse debate está na autonomia que é garantida a toda pessoa, e que deve ser especialmente discutida/problematizada quando se trata de mulheres privadas de liberdade.

2.1.1 Saúde da mulher em situação de cárcere: violações aos direitos sexuais e reprodutivos?

Mesmo com todos os avanços durante os tempos, delinquir tem seu preço, o sujeito é punido e paga pelo delito cometido. Até hoje, o que não mudou muito foi o modus pelo qual se cumpre a pena, haja vista que o Sistema Penitenciário Nacional, é marcado pela superlotação, baixa ressocialização, e sistemáticas violências que inviabilizam a função social da pena.

Tratando-se de estabelecimentos femininos, os problemas se agravam. Entre eles, as violações com relação a direitos sexuais e reprodutivos são uma das formas mais representativas da discriminação de gênero nesses espaços. Os estabelecimentos prisionais definitivamente não foram construídos para mulheres. É importante ressaltar que, segundo dados do Departamento Penitenciário NacionalDPN, existem apenas 58 presídios exclusivamente femininos, a maioria ainda é misto e não existe nenhum tipo de acesso voltado para mulheres (BRASIL, 2010). Sendo 
assim, é dispensado à mulher um tratamento desigual e inferior ao dado aos homens, são desrespeitadas as peculiaridades de "ser mulher".

A mulher encarcerada no Brasil não é vista quanto a sua condição de gênero, o crime prevalece a todo momento. Por exemplo, tendo em vista alguns aspectos como à visita íntima e social, o tema constrói-se sob uma perspectiva de inferioridade de gênero, haja vista, a disparidade entre as visitas para homens e mulheres encarceradas. Essa diferença um grande marcador, hoje, da condição masculina e feminina no cárcere. Enquanto muitas mulheres são abandonadas pelos companheiros no momento da prisão, constata-se, de modo inverso, que mulheres dificilmente abandonam o homem quando preso. Do mesmo modo, o abandono também é comum por parte da família ${ }^{3}$. Isso se dá pela desconstrução do tipo-ideal feminino. O preconceito de gênero é reforçado quando da ocorrência da criminalidade feminina.

Também, a visita íntima é algo que, mesmo regulamentada pela Resolução no 1, de 30 de março de 1999, do Conselho Nacional de Política Criminal e Penitenciária (CNPCP), ainda há muito o que se estruturar. A falta de privacidade dificulta as visitas, uma vez são feitas nas próprias celas, onde crianças e familiares dividem o mesmo espaço. Tratando-se sobre a visita íntima, o preconceito para com a mulher é algo recorrente. A mulher que tem o desejo da visita íntima é menosprezada, é como se neste local o desejo feminino não devesse ser manifestado (LIMA, 2006, p. 79.)

A assistência à saúde é outra violação que acontece diariamente na vida de mulheres presas. Essa população carcerária necessita de mais atenção à saúde do que a população em geral, como revela Mirabete, "[...] dentre os fatores que favorecem a alta incidência de problemas de saúde entre os presos está o estresse de seu encarceramento, condições insalubres, celas superlotadas com presos em contato físico contínuo e o abuso físico" (1997, p. 70).

Não obstante, mais uma violação no que tange um direito previsto nas Regras de Bangkok, na Lei de Execuções Penais e no Código de Processo Penal (CPP), a prisão domiciliar, é um direito que poucas vezes é exercido pelas gestantes em

\footnotetext{
${ }^{3}$ Contudo, outro empecilho que inibe os familiares de retornarem ao presidio é a revista vexatória e invasiva que é comum nos presídios brasileiros.
} 
situação de cárcere, pois é tido como privilégio. Ainda prevalece a lógica do punitivismo nesse contexto.

A Política Nacional de Saúde no Sistema Penitenciário é um projeto em conjunto do Ministério da Justiça e Ministério da Saúde, que tem como objetivo organizar o acesso da população penitenciária às ações e serviços do Sistema Único de saúde- SUS. Determinado direito já se encontra consolidado na Constituição Federal de 1988, pela Lei no 8.080, de 1990, que regulamenta o Sistema Único de Saúde, como também pela Lei de Execução Penal ํo 7.210, de 1984, e, mais recentemente, na Lei 11.942/2009 que garante direitos à saúde especificamente as mulheres que se encontram presas.

Quando uma mulher é recolhida ao estabelecimento prisional, vêm à tona os problemas de saúde, vícios, bem como transtornos mentais, que são gradualmente agravados pela precariedade das condições de moradia, alimentação e saúde das unidades prisionais.

Dentre as diretrizes adotadas pelo Plano estão: Prestar assistência integral resolutiva, contínua e de boa qualidade às necessidades de saúde da população penitenciária; Definir e implementar ações e serviços consoantes com os princípios e diretrizes do SUS; Provocar o reconhecimento da saúde como um direito da cidadania; entre outros (BRASIL, 2004).

Alguns critérios são estabelecidos para que Estados e Municípios possam aderir ao Plano, como a formalização do termo em envio ao Ministério da saúde; credenciamento dos estabelecimentos de saúde e aprovação dos planos operativos Estaduais pelo Ministério da saúde. Hoje, no Brasil, apenas 18 Estados fazem parte do PNSSP. Dentre eles está Pernambuco. Esses Estados contam com uma equipe de profissionais da área de saúde, que atuam desenvolvendo ações de atenção básica em estabelecimentos prisionais masculinos e femininos.

\section{OLHARES SOBRE MATERNIDADE E DIREITOS DE MULHERES PRESAS NA COLÔNIA PENAL FEMININA DE BUÍQUE/PE}

As categorias a seguir apresentam parte dos resultados da pesquisa que foi realizada na Colônia Penal Feminina de Buíque (CPFB), ao longo do ano de 2015, com Gestantes, lactantes, mulheres que tiveram seus filhos na Colônia, e estes já se encontram com outros familiares, e, por último, com a Chefia Executiva da CPFB. Ao 
estudar o cotidiano das mães e filhos/as, percebendo que contornos possui a maternidade no cárcere em questão, e de que maneira maternidade, condição de ser mulher e a prisão estão imbricadas, pudemos perceber os seguintes aspectos:

\subsection{CARACTERÍSTICAS DAS MÃES ENCARCERADAS}

Nesse momento vamos discutir as características das participantes da pesquisa. Foram entrevistadas 11 mulheres, dentre elas duas gestantes, seis lactantes e três que já haviam entregue seus filhos para suas respectivas famílias. Essas mães possuíam entre 18 e 31 anos de idade. Com relação a característica da cor da pele, apenas 4 são brancas e 7 são negras.

Outro dado relevante é que apenas duas dessas mulheres são mães pela primeira vez, as demais possuem outros filhos que se encontram fora da Colônia Penal Feminina de Buíque. Relata uma das participantes da pesquisa: "Tenho mais duas meninas e um menino, estão com minha mãe e irmã ${ }^{4}$ (Entrevistada 06)". Pelas repostas coletadas fica evidenciado um aspecto relacionado ao alcance das políticas de saúde pública quanto a prevenção de gravidez e planejamento familiar das entrevistas.

Sobre o grau de escolaridade, uma é analfabeta, três possuem ensino fundamental incompleto e sete delas têm ensino médio incompleto. Quanto à continuidade dos estudos, apenas três das entrevistadas estudam na escola que funciona dentro da CPFB. Vê-se que a política de reinserção é, ainda, de pouco alcance no processo de ressocialização. No que se refere a profissão das participantes da pesquisa, uma se diz agricultora, e as demais do lar, já quatro dizem que nunca ter trabalhado. A subsistência do grupo de entrevistadas se dá a partir de programas de transferência de renda, especialmente pelo Bolsa Família: "Tenho seis filhos, não tenho paciência pra estudo, aqui eu também não trabalho, aqui é muito difícil". (Entrevistada 09). Nota-se que a condição de criminalidade tem a vulnerabilidade que se encontravam as mulheres estudadas.

O considerável número de filhos, associado ao baixo nível de escolaridade, condiciona as mulheres entrevistadas ao trabalho materno e do lar. $O$ fato de não viverem com plena cidadania, a nosso ver, pode vir interferir na existência da criminalidade feminina. Ambientes escassos de cidadania e ausentes do Estado dão caminho a práticas ilícitas de sobrevivência. Podemos afirmar que o contexto de vulnerabilidade visto em relação as participantes da pesquisa é um fator que pode ser mensurado como possível abertura à prática de crimes, especialmente em situações que envolvem o tráfico de drogas.

As mães entrevistadas, em sua grande maioria, tinham como companheiros, homens que já viviam envolvidos com o crime e, de forma especial, com o tráfico de drogas, seja como traficantes ou usuários. Essas mulheres não eram viciadas em drogas, entraram para o mundo do crime ligadas pelo elo afetivo com algum sujeito próximo, em sua maioria homens.

Os delitos cometidos pelas mães entrevistadas dividem-se em: um homicídio, uma receptação e todos os demais tráfico. Outro dado relevante é que apenas duas mães das que foram detidas por tráfico não estavam levando a droga para o companheiro no presídio. Muito comum acontecer ocorrer que mulheres apenas por viverem na companhia de traficantes, quando estes são presos, a companhia também

\footnotetext{
${ }^{4}$ Foram mantidos possíveis erros de pronúncia como forma de sermos fiéis ao dito pelas entrevistadas.
} 
as coloca como cúmplices, como no relato a seguir: "Não dei sorte, fui levar pra meu marido, mas na hora de passar pela revista eu caí... de lá já vim direto pra cá, hoje tá nós dois preso" (Entrevistada 02)". É possível identificar que a mulher quando guarda ou transporta drogas para os estabelecimentos prisionais não faz apenas como meio de garantir o sustento da sua família, mas é resultado dos laços afetivos com o seu companheiro, como também menciona estudo de Costa (2008, p. 26).

Vê-se que a mulher quase nunca abandona seu companheiro quando este é preso, e sempre vai à visita e, nessas idas, acaba cedendo e levando droga para seu companheiro o que acarreta muitas vezes em sua prisão. Vale salientar, que o papel da mulher no tráfico é subsidiário. A elas é destinado um papel inferior, tido como "mula", a que leva a droga ao presídio ou "aviãozinho" aquela que vende pequenas quantidades.

Ainda, as mulheres entrevistadas vêm de um histórico de familiares presos. Como demonstra a pesquisa, apenas uma das entrevistas não possui um parente que cumpriu pena. Com relação aos pais das crianças em sua maioria encontram-se presos.

Quanto à assistência jurídica, apenas duas possuem advogados particulares, as demais são assistidas por dois advogados contratados pelo Estado para prestarem serviço na CPFB. Entre as que possuem advogado particular está a Entrevista 09: "Tenho advogada particular, já tô aqui faz três anos e um mês, mas ela não aparece faz seis meses, minha família vai pedir a ela os documentos e vai trocar, minha situação é muito complicada, eu ia entregar a droga a uma pessoa e essa pessoa ia entregar a outra, tô muito enrolada (Entrevistada 09).

As dificuldades dessas mulheres ficam evidenciadas na fala de todas, sem exceção. O Estado não oferta a elas uma assistência jurídica adequada. Tendo em vista que as demandas judicias são morosas, dois advogados não suprem a quantidade de processos existentes na CPFB.

A partir das informações coletadas nesta categoria, fica evidenciado que a condição econômica dessas mulheres é extremamente baixa, que a educação escolar oferecida para elas dentro da CPFB não tem nenhum atrativo que as façam ter vontade de estudar, o que as deixam ainda mais vulneráveis, tornando-as, muitas vezes, uma pessoa suscetível a reinserir-se no mundo do crime. A nosso ver, predomina a subalternização de gênero, classe e renda.

\subsection{ARQUITETURA PRISIONAL}

Aliada a tantas dificuldades que as mães e filhos passam nos estabelecimentos prisionais, a arquitetura prisional é mais uma delas. Percebe-se que os presídios não foram feitos para mulheres, são construídos por homens e para homens, tendo a administração prisional fazer modificações para adaptar às mulheres, muitas vezes não tendo condições estruturais de observar as peculiaridades femininas.

Atualmente existem em Pernambuco três locais destinados à reclusão de mulheres: as Colônias Penais Femininas do Recife, de Abreu e Lima e de Buíque. A CPFB, que têm capacidade para 109 mulheres, divididas em dois pavilhões com capacidade para o A de 70 e o B de 31 mulheres, tinha, ao longo da realização desta pesquisa, no regime fechado noventa mulheres sentenciadas, duzentos e quarenta e uma sumariadas, e no semiaberto dezenove mulheres aguardando a progressão, um total de trezentas e cinquenta presas. No entanto, desse total de mulheres, apenas 
quarenta são concessionadas, ou seja, trabalham e recebem algum benefício do Estado.

Um fato interessante é que, com relação as mulheres que esperam progressão de regime e/ou a prisão domiciliar, poucas entendem o seu direito. Dentre as mães entrevistadas apenas uma afirma ter reivindicado tal direito: "Já dei entrada na domiciliar, quero sair daqui junto com minha filha, se Deus quiser, aqui é um inferno, isso não é lugar para minha filha, ela não merece estar aqui" (Entrevistada 05). A prisão domiciliar é um direito previsto na Lei de Execuções Penais, mas que, conforme indagação durante a pesquisa, elas sequer sabem do direito que possuem, é como se essas mulheres não se vissem como sujeitos de direito.

Ainda sobre a arquitetura do local de estudo, a sala onde foram realizadas as entrevistas era um depósito com várias caixas, uma banca escolar e três cadeiras de plástico, a sala ficava entre a recepção e o berçário. Uma concessionada ficava abrindo a porta e organizando, uma mãe por vez. Durante todo o processo de entrevistas, as mães vinham acompanhadas de seus bebês, havia momentos em que amamentavam, ou, quando com os bebês maiores, as mães sempre mostravam o quanto eles eram espertos e inteligentes, nos mostrando as brincadeiras que eles faziam: "Ele tem oito meses, mostra mãe como tu desmaia, bate palminha pra ela ver como tu é sabido, esconde o rostinho, se esconde dela mãe (Entrevistada 04). A Entrevistada 05, que estava acompanhada da filha de apenas três dias, amamentava a criança durante a entrevista, e quando a bebê já estava satisfeita, seu leite começa a escorrer pela blusa. Pergunto se ela quer parar a entrevista, ela responde que não: "Graças a Deus tenho muito leite, vamos terminar". Há, claramente, a resistência do afeto como elemento que transpõe as condições ao exercício da maternidade.

É sabido que os presídios não foram pensados para abrigar mulheres, mas sim homens. Até nisso o fato da mulher sempre ser tida cuidadora do lar, dos filhos, do marido e não como passível de transgredir as leis, circunda o mesmo imaginário normativo que funda os espaços prisionais, marcados pelo patriarcalismo da lei e da dominação masculina. De modo claro, nada justificaria a mulher vir a delinquir. Nesta perspectiva, resta evidente o quanto as questões de gênero são marcantes, em todos os sentidos, nesse espaço. A condição feminina não é enxergada, a mulher é tratada como se homem fosse, o Estado não respeita as peculiaridades da mulher, nem mesmo as que estão grávidas na prisão.

Ainda, durante a entrevista com a chefia executiva, ficou evidenciado na fala da gestora o quanto o improviso para atender as questões peculiares à mulher em estado de privação de liberdade é uma constante: "Tudo aqui é improvisado, afinal de contas esse prédio foi construído para ser uma cadeia pública masculina, onde funciona a enfermaria seria a cela especial; uma sala grande foi dividida em duas para ser salas de aula, a outra sala de aula funciona no refeitório improvisada; o berçário seriam as celas para visitas íntimas. Se nós recebemos recursos, mas o dinheiro é escasso, infelizmente não dá pra fazer muita coisa" (Chefia Executiva).

O local onde funciona o "berçário" é marcado pelos desrespeitos à maternidade na prisão. Quatro quartos muito pequenos, com camas de cimentos e bi camas de madeira, onde se dividem mães, bebês e gestantes à espera do parto. Não há lugar para guardar seus objetos pessoais, acima das camas são estendidos arames com suas roupas, nas janelas com grades existem plásticos o que impede a ventilação. As paredes são, em sua grande parte, de cimento à mostra, o banheiro fica logo ao lado das camas. 
Em suma, não há qualquer respeito de garantias a mães e suas crianças: "Durmo na cama de cimento com meu filho, outra mãe e o filho dela, é muito pequeno, apertado pra gente" (Entrevistada 02). A fala da mãe chama atenção para os aspectos motores e de espaço, percebemos que o local que a mãe se refere, onde funciona o berçário, não apresenta condições de uma criança se desenvolver sadiamente. Afinal, além de abrigar muitas pessoas, o ambiente é precário em tamanho, as camas ocupam todo o espaço, o que impede a criança se locomover, tendo que passar boa parte do dia nos braços de sua genitora.

É visível, que a condição da mulher é negada nesse espaço. Elas, pela sua condição de gênero, merecem um olhar e atenção diferenciada, diferente da visão genérica das legislações, pois, muitas vezes, a interpretação ampla nega o direito à diferença a mulheres.

Constata-se, a partir da fala da Chefia Executiva, que o quadro tende a permanecer nessas condições. Afirma a Chefia que há um ano que não se recebe proventos para investimento na CPFB, evidenciando que o Estado, ao estruturar uma prisão feminina, não releva a condição de ser mulher e de suas necessidades básicas: "Não recebemos suprimentos para investimentos a praticamente um ano, como aqui é muito distante de tudo, como ficamos distante da capital, tudo fica mais difícil, inclusive de formarmos parcerias com empresas (Chefia Executiva).

Junto às questões da arquitetura prisional, vemos também os aspectos humanos desse espaço. A estrutura também é precária devido à falta de mão de obra especializada para o trabalho básico de limpeza, por exemplo. Nega-se também a essas mulheres a possibilidade de estar em um local mais apropriado a sua ressocialização.

Nessa categoria, a partir das análises, percebemos que, com relação a arquitetura prisional, o que predomina é um ambiente hostil, masculinizado, pensado e trabalhado em uma perspectiva de negação de peculiaridades femininas. Não há qualquer projeção no sentido de questionar o atual modelo do presídio feminino estudado.

\subsection{FILHO COMO APOIO EMOCIONAL PARA MÃE}

Durante toda pesquisa identificamos vários problemas institucionais, aliados inclusive a falta de compreensão de como o filho é importante para as mães presas, como a presença do filho acalma e traz para essas mulheres o sentido de responsabilidade, como as crianças representam a família destas mulheres. Para além da responsabilização pelos crimes cometidos, manter uma criança no ambiente prisional não é tarefa fácil para as mães. Como mencionado anteriormente, a falta de atenção do Estado para com esses pequenos sujeitos, aponta a precarização e a utopia da ressocialização no Brasil.

Muitas dessas mães ao serem separadas de seus filhos que já tinham antes de serem presas, estabelecem com essa nova criança um vínculo emocional ainda maior. Os sentimentos de culpa e aqueles advindos da nova maternidade criam um quadro de sofrimento e de dor, como relata a Entrevistada 06, que, na época da pesquisa, estava gestante: "Tenho mais 3 filhos, 2 meninas e 1 menino, esse é outro menino. Vou ficar com ele o tempo que eu puder aqui pra me fazer companhia, é muito difícil esse lugar e a pessoa sozinha, pior ainda". A fala da entrevistada evidencia não só o sentimento de solidão, mas do próprio ócio que permeia esse espaço, verdadeiro depósito de pessoas. 
Enquanto presas, essas mulheres não têm domínio sobre suas próprias vidas, o Estado que disciplina como elas e os filhos devem viver, estabelecendo regras principalmente no que diz respeito a criação das crianças que estão diretamente sobre a tutela do Estado, conjuntamente com suas genitoras. A impossibilidade de exercer a maternidade no cárcere é uma grande violação de direitos dessas mulheres. São percebidas e expressas por elas as diferenças que permeiam as violações de seus direitos reprodutivos nesses espaços, a ponto que apontam a maternidade como sendo um direito impossível de ser exercido no cárcere.

$\mathrm{Na}$ CPFB, $60 \%$ das mulheres são da cidade de Caruaru, cidade muito distante de Buíque. Essa geografia dificulta, em grande escala, a presença de outros membros da família nas visitas. A pena deve atingir apenas a pessoa da detenta, e não a criança. $O$ processo de isolamento constatado evidencia que os/as filho/as das detentas sofrem de modo muito peculiar a pena importas às mães.

A criança, muitas vezes, é a única referência de família que as mulheres têm, pois, a visitação não ocorre com frequência: "Recebo visita de seis em seis mês, as condição tá muito difícil lá fora também, minha mãe não tem dinheiro pra tá aqui toda semana, aí fica faltando muita coisa pra ele" (Entrevistada 02). Como nesse caso, a ausência da família indica não só que faltam itens para a subsistência da criança, mas que o Estado não proporciona nenhum item destinado aos bebês. Apesar de haverem normas que determinam que os filhos permaneçam com suas mães - uma espécie de controle punitivo do Estado sobre o corpo - não há nenhum tipo de cuidado com a subsistência das crianças. O Estado termina por desempenhar e evidenciar sua face mais evidente, a do castigo.

Entretanto, a Lei estabelece que a criança deve permanecer com a mãe até o período de amamentação, mas o que seria esse tempo de amamentação, haja vista, que necessidades são diferentes, como evidencia e destaca a entrevistada 09: "Ele tem onze meses e ainda mama, ainda bem porque minha mãe não pode vir me visitar, porque eu tenho um irmão cadeirante que ela toma conta, quem já vem aqui e traz as coisas pra ele é meu sogro, como ele tá grandinho tenho que inteirar com mingau, mas ele ainda pede o peito (Entrevistada 09). Mas uma vez a fala da mãe evidencia como a Lei é frágil e omissa com relação as crianças que vivem em estabelecimento prisional. O Estado não oferece alimentação para essas crianças, afinal, não contempla, na prisão, as peculiaridades de ser mãe e presa.

Em suma, os dados coletados nesta categoria evidenciaram que o local destinado ao cuidado com crianças, na prisão estudada, não é adequado. Ainda, que as crianças na CPFB estão expostas a condições indignas de subsistência, as quais constroem o aprisionamento como uma extensão da pena aos/as filhos/as das mães entrevistadas.

\subsection{CONDIÇÃO DE SER MÃE NO CÁRCERE}

A condição delicada da mulher mãe em situação de cárcere começa assim que ela é presa grávida, ou mesmo quando se desconfia que está grávida. A mulher que ingressa grávida de até seis meses na CPFB não é levada ao pavilhão específico desse grupo, permanece junto com as demais presas, dividindo espaços, como se grávida não estivesse.

A partir das entrevistas percebemos como estas mulheres viviam durante a gestação na CPFB, demonstrando que, mesmo grávidas, prevalece apenas o delito cometido, o seu estado não é respeitado pelo Estado. Vejamos: "Não sabia que estava 
grávida quando cheguei aqui, fiz exame demorou muito tempo pra chegar o resultado. Eu dormia no colchão de solteiro com uma mulher muito boa, ela era como uma mãe pra mim, (choro), tinha muito cuidado pra não bater em mim, ela dormia pra cima e eu pra baixo, fiquei lá até o 7 mês" (Entrevistada 07).

Aliado a esse quadro, os itens de higiene pessoal são de responsabilidade das próprias detentas, ficando na dependência do que seus familiares possam levar durante a visita. Itens básicos como: creme dental, sabonete, shampoo e o que todas mulheres necessitam todos os meses como, por exemplo, absorventes, não é disponibilizado pelo Estado. Os direitos reprodutivos encontram grande obstáculo na não afirmação da saúde nesses espaços. A sororidade é sentimento que possibilita a afirmação das questões de gênero nesse espaço: "Só recebo visita uma vez no mês, falta tudo aqui, muito difícil estar nesse lugar". As meninas que recebem visita me ajudam, aqui uma ajuda a outra, porque a gente só recebe a comida e agora teve cortes até nisso" (Entrevistada 04). O presente estudo aponta que o Estado é omisso para com mulheres presas.

Mesmo em relação ao nascimento dos bebês, direito básico à vida, para maioria das mulheres entrevistadas que estão na CPFB, constitui-se em uma peregrinação e desafio. No município de Buíque a falta de estrutura no Hospital impede que sejam realizadas cesarianas, então só as mães que têm seus filhos de parto natural parem no município. As demais, que necessitam de uma cesariana são levadas até as cidades de Arcoverde ou Caruaru.

Além da incerteza, de onde e como terão seus filhos, um problema de segurança pública afeta essas mulheres na hora do parto, como relata a Chefia Executiva: "Temos pouco efetivo de maneira geral, e efetivo de mulheres menos ainda, e durante a custódia nos hospitais, não são aceitos homens, é uma grande dificuldade pra gente poder administrar essa situação" (Chefia Executiva). Percebese que a questão de segurança pública, aliada à superlotação do sistema carcerário, não releva a necessidade de serviços especializados para a mulher-mãe. Assim, é explícito durante a pesquisa a falta de reconhecimento das mulheres presas enquanto sujeitos de direito. São retiras delas quaisquer aspectos de humanidade.

Conclui-se, nesta categoria, o quanto as condições sub-humanas do espaço e do sistema prisional impedem o respeito à dignidade e ao exercício da maternidade. Sob as regras do estabelecimento prisional, a mulher não escolhe como criar o filho, as violações são uma constante, a realidade encontrada é de total exclusão, marcada por uma dissimulada discriminação de gênero que viola direitos e a condição de ser mulher.

\subsection{ASPECTOS SOBRE A LEI 11.942/2009: DESCOMPASSOS E HORIZONTES}

O universo da mulher grávida em situação de cárcere merece cada vez mais atenção, pois as peculiaridades do ser mulher, mãe e de ter em sua companhia um/a filho/a no estabelecimento prisional requer tratamento diferenciado de um preso masculino. Pensando nisso foi criada a Lei 11.942 de 2009, na verdade uma alteração aos artigos 14, 83 e 89 da Lei de Execuções Penais (LEP). No que tange a como esta norma é aplicada na CPFB, ou seja, de como o Estado e a administração prisional 
colocam em prática a referida Lei, vê-se que mães e os/as filhos/as que vivem no estabelecimento Prisional não têm seus direitos estabelecidos e/ou cumpridos.

Traçando um paralelo entre o que determina a mencionada legislação vigente e a rotina na CPFB, percebe-se que a Lei não é aplicada: em seu art. 14, §3º que dispõe sobre o acompanhamento médico à mulher e a criança, vemos a partir da fala da Chefia Executiva que, com relação à saúde da mulher e do filho, existem na Unidade Prisional, um médico ginecologista e uma enfermeira, que atendem três vezes por semana, apenas. Também constatamos que existe um projeto chamado "Módulo de Saúde", que visa transformar o prédio anexo, onde hoje funciona o semiaberto, em uma área totalmente voltada para saúde da mulher. Porém, durante as entrevistas, as mães explicam que qualquer problema de saúde que as crianças sofrem são encaminhadas aos postos de saúde do município de Buíque: "Ele (criança) caiu e elas (agentes) levaram na hora para o postinho". Percebe-se que o atendimento à mãe e a criança é feito de maneira pontual, e por meio de encaminhamento à Rede Municipal e Estadual de Saúde, ou seja, pelo SUS.

A Lei também determina a criação de berçários para amamentação e creche para as crianças menores de 7 (sete) anos. Contudo, na CPFB, não existe berçário nem creche, desrespeitando o dispositivo legal, haja vista, que o local é uma cadeia masculina improvisada sem a menor estrutura para abrigar mulheres, muito menos mães e crianças.

O chamado "berçário", é, na verdade, quatro celas pequenas onde dormem mães, bebês e gestantes que vêm dos demais pavilhões entre o sexto e o sétimo mês de gestação. O local é totalmente inadequado para que mães e filhos/as desenvolvam qualquer atividade. $\mathrm{O}$ ambiente físico é contrário ao que dispõe a Legislação e não oferece a criança oportunidade de locomoção: "Meu filho não pode correr, vive ou na cama ou no braço" (Entrevistada 09).

A CPFB, não possui creche, tampouco pessoal qualificado para dar assistência às crianças. $O$ que se constata, em relação a este item da Lei é de que a normativa é omissa quanto à assistência. A nosso ver, a execução das penas não observa as peculiaridades e as verdadeiras necessidades de mães e filhos.

Com relação a amamentação, a Constituição Federal em seu art. 5ํㅡ, L, a Lei de Execuções Penais e o Estatuto da Criança e do Adolescente, estabelecem o direito 
da criança de ser amamentada pela mãe, mesmo estando em unidade prisional. A Lei 11.942 de 2009, determina, ainda, que os presídios devem estar dotados de local apropriado para que a mãe possa amamentar seu filho até os seis meses de vida, como também de creches para abrigar crianças menores de sete anos. No entanto, a respeito de garantias à mãe que, por motivos de saúde não pode amamentar seu/sua filho/a, ou no caso de que ele/a já se encontre com mais de seis meses, precisando de outro tipo de alimentação, não faz menção a Lei sobre essa garantia. Com relação a falta de alimentação para as crianças, vejamos: "Tive um problema nos meus peitos, fiz de tudo pra dar de mamar, mas cresceu uns caroços no meu peito e ficou muito duro, ela ia mamar e saia sangue, como não tinha como comprar leite Nãn era $R \$ 35$, 00 a lata, aí mandei ela pra casa com dois meses" (Entrevistada 10).

Constata-se, que em relação à subsistência da criança, há uma lacuna clara na Lei 11.942 de 2009 em relação a bebês que não mamam e aqueles maiores de seis meses que não precisam somente do leite materno. Na CPFB só se disponibiliza cerca de 120 fraldas por mês para aquelas crianças que lá convivem com suas mães, além de alguns remédios. A fala a seguir deixa evidente o quanto o Estado é omisso: "Falta muita coisa, são só 120 fraldas no mês e a gente tem que render, quem tem visita é bom, mas eu que não tenho visita tenho que me virar, aí no domingo as meninas faz cotinha e me dão dinheiro pra mandar os agentes comprar fralda e leite pra ela, já misturei massa com água" (Entrevistada 02).

Contudo, ao analisarmos esta categoria, juntamente com as falas dos sujeitos da pesquisa, ficou evidenciado que a Lei 11.942 de 2009 não é cumprida. Como relatado pela Chefia Executiva, por diversas vezes, a CPFB foi construída para ser uma cadeia pública masculina, fato este que impede, desde sua arquitetura, o exercício de direitos reprodutivos de mulheres.

\subsection{MOMENTO DA SEPARAÇÃO}

Nesta categoria iremos analisar um aspecto imprescindível sobre o tema que estamos discutindo, o momento da separação entre mães e filhos que vivem em estabelecimentos prisionais. Nesta categoria iremos relatar a omissão da Lei sobre o tempo de permanência da criança junto à mãe e a realidade vista na CPFB, e, por fim, a partir de que aspectos se dá essa separação.

O vínculo criado entre mãe e bebê dá suporte e ajuda a mãe no cumprimento da pena. Sendo a companhia desta mulher, o filho minimiza o exacerbado punitivismo do Estado. Durante conversa com a Chefia Executiva, na CPFB, ficou evidenciado 
que a regra para que crianças e mães dormissem na mesma cama dar-se-ia por motivos sentimentais, como dispõe a seguir: "Os berços foram abolidos, pois as mães não utilizavam, e é difícil obrigar, acho que pelo pouco tempo que passam com os filhos preferem dormir abraçadas a eles"(Chefia Executiva). Na verdade, esse quadro invisibiliza a precariedade quanto ao cuidado e as condições oferecidas no sistema prisional feminino.

Com relação ao critério de separação, na CPFB, se dá por volta dos seis meses de vida do bebê. Todas as mães entrevistadas, sem exceção, falam que é melhor o filho fora da prisão, mas, ao mesmo tempo, expressam muito sofrimento ao falarem do momento da separação entre eles/as. Seja as que já passaram por este momento, como as que estão perto de vivenciarem este terrível e doloroso dia, há pouco preparo em relação ao momento da separação, como expõe, abraçada ao filho e chorando, a Entrevistada 02: "Domingo mãe vem buscar ele, não gosto nem de falar, vou ficar muito tempo sem ver ele, porque mãe não tem dinheiro pra vir me ver, passa seis mês para vir, acho que ele nem vai mais me conhecer".

Ao analisarmos a fala acima, fica evidente o sofrimento dessas mulheres. Certamente, o trauma em serem separadas, tanto para mães como para filhos/as, terá condições nefastas. Falta, ao Estado, implementar mecanismos que viabilizem a plena ressocialização dessas mulheres como caminho a um futuro reencontro. A entrevistada 09 descreve o dia que sua filha separada dela: "Era dia trinta de dezembro, me agarrei com ela e gritava pra ela não ir, pedi tanto que deixassem eu passar o ano novo com ela, mas não teve jeito. A menina foi embora eu chorei tanto, foi uma dor tão grande que eu nunca senti uma coisa daquela. Vim aqui falar com a senhora, mas não olhei pra o berçário, eu não gosto de ficar vendo as outras mães com os filhos, eu lembro muito dela, quando ela foi embora pedi na mesma hora pra subir pra o pavilhão". Esse conjunto de sentimentos, na fala da entrevista, reflete o duro caminho ao exercício da maternidade no cárcere. Após a separação, o tempo para as mães entrevistadas é um inimigo, a ausência dos/as filhos/as tolhe suas perspectivas de vida.

Ao longo da entrevista, a entrevistada 08 nos chamou atenção: seu filho está com onze meses na CPFB, ele não foi embora ainda pois houve um erro no registro de nascimento, precisamente no nome da mãe, que está aguardando a correção para que ele possa ir embora: "Assim que chegar ele irá embora", diz a mãe em tom de tristeza. Mãe e filho, durante toda entrevista, se olham muito, e é notória a cumplicidade existente naquela relação. Um fato comum foi que, durante as entrevistas, pessoas que nos acompanhavam seguram os bebês no colo para que as mães ficassem mais à vontade. No entanto essa entrevistada segurou e abraçou a criança durante toda a entrevista, inclusive não permitindo que outras pessoas o pegassem no colo: "Ele só é acostumado comigo, né mãe? Ele não vai pra o braço dos outros não (Entrevistada 08). Questiona-se: como o Estado poderá garantir o exercício de direitos reprodutivos a essa e outras mulheres, agindo de modo tão alheio às questões de gênero?

Nesta categoria, fica evidente que o momento de separação é, sem dúvidas, o grande gargalo desse cenário. Este momento é feito sem nenhum preparo, o laço é rompido de forma brusca, o critério de separação é aleatório e a cargo da administração do estabelecimento prisional. Leva-se em consideração apenas o que é melhor para a administração prisional, e não o que é melhor para criança e/ou para a mulher. 


\section{CONCLUSÃO}

Constatamos, em relação a problemática eleita, que a forma como vivem mães que cumprem pena privativa de liberdade na companhia de seus filhos na Colônia Penal Feminina de Buíque/PE é extremamente discrepante e contrária ao que diz respeito às Leis que versam sobre o assunto, especialmente a Lei oㅜ 11.942/2009.

As condições em que vivem mães e filhos, contempla uma realidade comovente na qual fica clara a negação da condição de ser mulher. Um elemento base percebido é que o sistema carcerário, ao negar as peculiaridades existentes no mundo de mulheres mães, comete violações e injustiças que as punem duplamente. Ainda, constata-se que há um grande esforço por parte da administração prisional da Colônia estudada para adaptar o local para o universo feminino, tendo em vista que o prédio foi construído para ser uma cadeia pública masculina.

A legislação determina que os presídios femininos devem ser dotados de berçário para amamentação. Ademais, na CPBF, não existe esse tipo de espaço, mas um local improvisado que em nada parece com o que determina a legislação, a falta de ventilação, pouco espaço para locomoção das crianças, péssimas acomodações, é o que se constata nesse ambiente. A pesquisa mostra também que, apesar da legislação assegurar que crianças têm o direito de permanecer com sua mãe no estabelecimento prisional, o local não é adequado para uma convivência sadia e saudável. O fato é que o local não está preparado para receber mães, tampouco, seus filhos, as condições ofertadas são extremamente precárias.

Quanto ao período de permanência das crianças nos estabelecimentos prisionais, a legislação trata apenas do período mínimo, que é o da amamentação, já o período máximo de convivência é um ponto de omissão do legislador, ficando o critério da separação com a diretoria dos estabelecimentos prisionais. Especificamente, na CPFB, o prazo máximo é o de seis meses de idade, devido à falta de estrutura em acomodar essa criança.

Ainda em relação as omissões da legislação quanto às peculiaridades da mulher no cárcere, está o da subsistência dessa criança. O Estado não oferta nenhum tipo de ajuda, ficando a mãe com o dever de arcar com a subsistência da criança. Portanto, a mãe que por qualquer motivo não possa alimentar seu filho com leite 
materno, terá que arcar com a alimentação do seu filho. Vê-se que a estrutura física e a omissão legislativa são fatores que levam a uma gama de violações a mães e seus filhos.

É inquestionável que a convivência entre mães e filhos é de fundamental importância, principalmente no início da vida da criança, devendo se dar em condições dignas de sobrevivência. Contatou-se que, mesmo em condições precárias no cárcere, as mães entrevistadas querem seus filhos por perto, acreditam que eles estão melhor em suas companhias.

Tendo em vista o abandono que essas mulheres sofrem ao serem presas, seja pelo companheiro, seja pela própria família, na pesquisa, o fato da Colônia Penal Fermina de Buíque ter uma localização de difícil acesso, faz com muitas mães recebem poucas ou nenhuma visita. As condições financeiras das mães entrevistas e de suas famílias não permitem que a visita aconteça com frequência, ou os maridos já não mais convivem com elas.

Constata-se ainda, que o número crescente das mulheres nos estabelecimentos prisionais, aponta que o Estado deve voltar seus olhos para as necessidades das mulheres, pois o tratamento ofertado é o mesmo para homens e mulheres, negando sempre a condição feminina. Desta forma, conclui-se que mesmo havendo leis que asseguram muitos direitos às mães em cumprimento de pena privativa de liberdade que convivem com seus filhos no cárcere, elas ainda estão pendentes de eficácia. Como também, os legisladores precisam enxergar as necessidades femininas, afirmando seus direitos.

\section{REFERÊNCIAS}

BRASIL. Decreto Lei no 3, de 03 de outubro de 1941. Brasília: Senado,1941. . Lei 7210/1984. Lei de Execução Penal. Brasília: Senado, 1984.

. Constituição da República Federativa do Brasil. Brasília: Senado, 1988.

Plano Nacional de Saúde no Sistema Carcerário. 1. Ed. Brasília: Ministério da Saúde, 2004.

. Lei 11.942, de 28 de maio de 2009 - dá nova redação aos arts. 14, 83 e 89 da Lei no 7.210, de 11 de julho de 1984 - Lei de Execução Penal. Brasília: Senado, 2009. 
Conselho Nacional de Política Criminal e Penitenciário- CNPCP. Resolução no 3 de 15 de julho de 2009. Brasília: Ministério da Justiça, 2009.

Principais Dificuldades Enfrentadas Pelas Mulheres Privadas de Liberdade. Brasília: Ministério da Justiça, 2010.

COSTA, Elaine Cristina Pimentel. Amor bandido: as teias afetivas que envolvem a mulher no tráfico de drogas. Maceió: EDUFAL, 2008.

LIMA, Renato. $O$ decreto n. 5.948/2006 e o ciclo das políticas públicas de justiça e segurança. Política Nacional de Enfrentamento ao Tráfico de Pessoas. Brasília: Ministério da Justiça, 2006.

MIRABETE, Julio Fabbrini. Execução Penal. 10. ed. São Paulo: Atlas, 2002.

ORGANIZAÇÃO DAS NAÇÕES UNIDAS. Declaração Universal dos Direitos Humanos - Adotada e proclamada pela Resolução 217 A da Assembleia Geral das Nações. ONU, 1948.

. Convenção sobre a eliminação de todas as formas de discriminação contra a mulher. ONU: México, 1979.

- Relatório da Conferência Internacional sobre População e Desenvolvimento. ONU: Cairo, 1994.

Convenção interamericana para prevenir, punir e erradicar a violência contra a mulher. Convenção Belém do Pará. Brasil: Ministério da Justiça, 1994.

. Conferência Mundial sobre a Mulher: Igualdade, Desenvolvimento e Paz. ONU: Pequim, 1995.

Regras Mínimas para o Tratamento das Presas e Medidas não Privativas de Liberdade para Mulheres que Cometem Crimes (Regras de Bangkok). ONU: Bangkok, 2010.

RIOS, Roger Raupp. Em defesa dos direitos sexuais. Porto Alegre: Liv. do Advogado, 2007.

SAFFIOTI, Heleieth lara Bongiovani. Rearticulando gênero e classe social. In: COSTA, A. O.; BRUSCHINI, C. (Orgs.). Uma questão de gênero. Rio de Janeiro: Rosa dos Tempos, 1992. 